\title{
Radioactive lodine Activities for Postsurgical Thyroid Ablation: The Lower the Better
}

\author{
Furio Pacini \\ Department of Internal Medicine, Endocrinology and Metabolism and Biochemistry, Section of Endocrinology and \\ Metabolism, University of Siena, Siena, Italy
}

The initial treatment of differentiated thyroid cancer consists of total or near-total thyroidectomy. Surgery is usually followed by the administration of radioactive iodine activities (RAI) aimed to ablate any remnant thyroid tissue and potential microscopic residual tumor. It is still controversial whether this procedure may have an influence on the mortality rate, but in most series it seems to reduce the risk of regional recurrence and facilitates longterm surveillance based on serum thyroglobulin $(\mathrm{Tg})$ measurement and diagnostic radioiodine whole body scan (WBS). According to several guidelines $[1,2]$ the recommendations for remnant thyroid ablation are modulated on the basis of risk factors. RAI ablation is indicated in high-risk patients (those with documented, or strongly suspected, residual disease), whereas it is not indicated in very low-risk patients (those with unifocal microcarcinomas, no metastases, and favorable histology). In patients at intermediate risk (those in between the low and high risk), remnant ablation may be indicated but the decision must be individualized.

Effective thyroid ablation requires adequate stimulation by TSH. This may be achieved by thyroid hormone withdrawal (THW) or after recombinant human TSH (rhTSH) administration. The last procedure is considered the method of choice based on several reports [3-5] demonstrating equal efficacy of rhTSH compared to THW. rhTSH-assisted RAI ablative therapy is associated with similar rates of persistent disease and clinical recurrences than those observed after traditional THW preparation, at least in the short-term follow-up [6, 7]. In addition, preparation with either rhTSH or THW appears to have similar adjuvant effects on small-volume RAI-avid disease identified outside the thyroid bed at the time of initial RAI ablation $[4,8]$.

A still controversial issue is the choice of the radioiodine activity to be administered at the time of ablation. ATA [1] and ETA [2] guidelines (dated 2009 and 2006, respectively) recommend the use of 30 - to 100 -mCi doses of radioiodine for low-risk patients and higher doses (>100 mCi) for high-risk patients. However, such indications are not based on strong clinical evidence but rather on expert opinion derived mainly from retrospective uncontrolled studies. Only recently, two large prospective, randomized, multicenter studies, one in France [9] and one in the UK [10] simultaneously published in the New England Journal of Medicine, compared the results of thyroid ablation performed after THW versus rhTSH and using 30 versus $100 \mathrm{mCi}$.

KARGER
Fax +4161306 1234
E-Mail karger@karger.com
www.karger.com

(C) 2012 European Thyroid Association Published by S. Karger AG, Basel $2235-0640 / 12 / 0014-0213 \$ 38.00 / 0$ Accessible online at: www.karger.com/etj
Furio Pacini, MD

Sezione di Endocrinologia, University of Siena

Via Bracci

IT-53100 Siena (Italy)

E-Mail pacini8@unisi.it 
In both studies, inclusion criteria were: an age of 18 years or older; total thyroidectomy for differentiated thyroid carcinoma; tumor-node-metastasis (TNM) stage, ascertained on pathological examination of a surgical specimen, of pT1-T2 and any N stage (pT3 were also included in the UK study), and absence of distant metastasis. Thyroid ablation was assessed 6-9 months after RAI ablation by neck ultrasonography and measurement of rhTSH-stimulated Tg in the French study and, in addition, by diagnostic radioiodine WBS in the UK study.

In the French study [9], out of 684 patients with data that could be evaluated, ultrasonography of the neck was normal in 652 (95\%), and the stimulated $\mathrm{Tg}$ level was $\leq 1.0 \mathrm{ng} / \mathrm{ml}$ in 621 of the 652 patients (95\%) without detectable $\mathrm{Tg}$ antibodies. Thyroid ablation was complete in 631 of the 684 patients (92\%). The ablation rate was equivalent between the iodine-131 doses and between the thyrotropin-stimulation methods.

In the UK study [10], data could be analyzed in 421 patients. Ablation success rates were $85.0 \%$ in the group receiving low-dose radioiodine versus $88.9 \%$ in the group receiving the high dose and $87.1 \%$ in the rhTSH group versus $86.7 \%$ in the group undergoing THW. All 95\% CI for the differences were within \pm 10 percentage points, indicating noninferiority. Similar results were found for low-dose radioiodine plus rhTSH (84.3\%) versus highdose radioiodine plus THW (87.6\%) or high-dose radioiodine plus rhTSH (90.2\%). Of additional interest is the finding that the low-dose protocol was associated with fewer days of hospitalization and that the proportions of patients with adverse events were lower in the low-dose group versus the high-dose group and in the rhTSH group versus the THW group. As expected, symptoms of hypothyroidism and quality of life were significantly better in the rhTSH-treated groups.

The message of these clinical trials is very clear: low doses of radioactive iodine after preparation with rhTSH have similar ablation rates compared with high doses and THW, with the advantage of fewer side effects, shorter or no hospital stay, and better quality of life. Of course, the two studies cannot answer the question of whether the rate of recurrences in a long-term follow-up will be the same. However, based on retrospective available data showing that less than $1 \%$ of patients with low-risk cancer who had normal neck ultrasonography and an undetectable rhTSH-stimulated serum Tg level will have a clinical recurrence over a 10- to 15-year period [11-13], we can be confident that the long-term outcome of the patients enrolled in the French and UK studies will confirm their favorable outcome. While awaiting these results, my personal opinion is that whenever thyroid ablation is indicated in low- or intermediate-risk patients with differentiated thyroid cancer, the 30 -mCi dose after preparation with rhTSH should be the standard of care.

\section{Disclosure Statement}

Dr. Pacini has been a consultant and acted as a lecturer for Genzyme.

\section{References}

1 Cooper DS, Doherty GM, Haugen BR, Kloos RT, Lee SL, Mandel SJ, Mazzaferri EL, McIver B, Pacini F, Schlumberger M, Sherman SI, Steward DL, Tuttle RM: Revised American Thyroid Association management guidelines for patients with thyroid nodules and differentiated thyroid cancer. Thyroid 2009; 19:1167-1214.

-2 Pacini F, Schlumberger M, Dralle H, Elisei R, Smit JW, Wiersinga W, European Thyroid Cancer Taskforce: European consensus for the management of patients with differentiated thyroid carcinoma of the follicular epithelium. Eur J Endocrinol 2006;154:787803.

3 Pacini F, Ladenson PW, Schlumberger M, Driedger A, Luster M, Kloos RT, Sherman S, Haugen B, Corone C, Molinaro E, Elisei R, Ceccarelli C, Pinchera A, Wahl RL, Leboulleux S, Ricard M, Yoo J, Busaidy NL, Delpassand E, Hanscheid H, Felbinger R, Lassmann
M, Reiners C: Radioiodine ablation of thyroid remnants after preparation with recombinant human thyrotropin in differentiated thyroid carcinoma: results of an international, randomized, controlled study. J Clin Endocrinol 2006;91:926-932.

4 Pilli T, Brianzoni E, Capoccetti F, Castagna MG, Fattori S, Poggiu A, Rossi G, Ferretti F, Guarino E, Burroni L, Vattimo A, Cipri C, Pacini F: A comparison of $1,850(50 \mathrm{mCi})$ and $3,700 \mathrm{MBq}(100 \mathrm{mCi})$ 131-iodine administered doses for recombinant thyrotropinstimulated postoperative thyroid remnant ablation in differentiated thyroid cancer. J Clin Endocrinol Metab 2007;92:3542-3546.

5 Chianelli M, Todino V, Graziano FM, Panunzi C, Pace D, Guglielmi R, Signore A, Papini E: Low-activity (2.0 GBq; $54 \mathrm{mCi})$ radioiodine post-surgical remnant ablation in thyroid cancer: comparison between hormone withdrawal and use of rhTSH in low- risk patients. Eur J Endocrinol 2009; 160: 431-436.

-6 Elisei R, Schlumberger M, Driedger A, Reiners C, Kloos RT, Sherman SI, Haugen B, Corone C, Molinaro E, Grasso L, Leboulleux S, Rachinsky I, Luster M, Lassmann M, Busaidy NL, Wahl RL, Pacini F, Cho SY, Magner J, Pinchera A, Ladenson PW: Follow-up of low-risk differentiated thyroid cancer patients who underwent radioiodine ablation of postsurgical thyroid remnants after either recombinant human thyrotropin or thyroid hormone withdrawal. J Clin Endocrinol Metab 2009;94:4171-4179.

7 Tuttle RM, Brokhin M, Omry G, Martorella AJ, Larson SM, Grewal RK, Fleisher M, Robbins RJ: Recombinant human TSH-assisted radioactive iodine remnant ablation achieves short-term clinical recurrence rates similar to those of traditional thyroid hormone withdrawal. J Nucl Med 2008 49:764-770. 
8 Tuttle RM, Lopez N, Leboeuf R, Minkowitz SM, Grewal R, Brokhin M, Omry G, Larson $S$ : Radioactive iodine administered for thyroid remnant ablation following recombinant human thyroid stimulating hormone preparation also has an important adjuvant therapy function. Thyroid 2010;20:257-263.

$\checkmark 9$ Schlumberger M, Catargi B, Borget I, Deandreis D, Zerdoud S, Bridji B, Bardet S, Leenhardt L, Bastie D, Schvartz C, Vera P, Morel O, Benisvy D, Bournaud C, Bonichon F, Dejax C, Toubert ME, Leboulleux S, Ricard M, Benhamou E, Tumeurs de la Thyroïde Refractaires Network for the Essai Stimulation Ablation Equivalence Trial: Strategies of radioiodine ablation in patients with low-risk thyroid cancer. N Engl J Med 2012;366:16631673.
10 Mallick U, Harmer C, Yap B, Wadsley J, Clarke S, Moss L, Nicol A, Clark PM, Farnell K, McCready R, Smellie J, Franklyn JA, John R, Nutting CM, Newbold K, Lemon C, Gerrard G, Abdel-Hamid A, Hardman J, Macias E, Roques T, Whitaker S, Vijayan R, Alvarez P, Beare S, Forsyth S, Kadalayil L, Hackshaw A: Ablation with low-dose radioiodine and thyrotropin alfa in thyroid cancer. N Engl J Med 2012;366:1674-1685.

11 Cailleux AF, Baudin E, Travagli JP, Ricard $\mathrm{M}$, Schlumberger $\mathrm{M}$ : Is diagnostic iodine131 scanning useful after total thyroid ablation for differentiated thyroid cancer? J Clin Endocrinol Metab 2000;85:175-178.
2 Pacini F, Capezzone M, Elisei R, Ceccarelli C, Taddei D, Pinchera A: Diagnostic 131-iodine whole-body scan may be avoided in thyroid cancer patients who have undetectable stimulated serum Tg levels after initial treatment. J Clin Endocrinol Metab 2002;87: 1499-1501.

13 Castagna MG, Brilli L, Pilli T, et al: Limited value of repeat recombinant human thyrotropin (rhTSH)-stimulated thyroglobulin testing in differentiated thyroid carcinoma patients with previous negative rhTSH-stimulated thyroglobulin and undetectable basal serum thyroglobulin levels. J Clin Endocrinol Metab 2008;93:76-81. 